\title{
On the corrosion resistance of AISI 316L-type stainless steel coated with manganese and annealed with flow of oxygen
}

\author{
Hadi Savaloni $^{1} \cdot$ Ensieh Agha-Taheri $^{2} \cdot$ Fateme Abdi $^{1}$
}

Received: 8 February 2016/Accepted: 23 February 2016/Published online: 17 March 2016

(C) The Author(s) 2016. This article is published with open access at Springerlink.com

\begin{abstract}
AISI 316L-type stainless steel was coated with $300-n m-t h i c k$ Mn thin films and post-annealed at $673 \mathrm{~K}$ with a constant flow of oxygen $\left(250 \mathrm{~cm}^{3} / \mathrm{min}\right)$. The films crystallographic and morphological structures were analyzed using X-ray diffraction (XRD) and atomic force microscopy (AFM) before corrosion test and scanning electron microscopy (SEM) after corrosion test. Corrosion behavior of the samples in $0.3,0.5$ and $0.6 \mathrm{M} \mathrm{NaCl}$ solutions was investigated by means of potentiodynamic and electrochemical impedance spectroscopy (EIS) techniques. Results showed that the corrosion inhibition of annealed $\mathrm{Mn} / \mathrm{SS} 316 \mathrm{~L}$ in all $\mathrm{NaCl}$ solutions with different concentrations is higher than that of bare SS316L. A correlation is achieved between the structural variation of the films with the potentiodynamic and EIS corrosion results.
\end{abstract}

Keywords $\mathrm{MnO} \cdot$ Stainless steel $\cdot$ Thin film · Annealing · Corrosion resistance $\cdot$ Electrochemical impedance spectroscopy (EIS) $\cdot$ Potentiodynamic

\section{Introduction}

Corrosion is one of the main reasons of surface damage and it strongly influences metals lifetime. Therefore, in the present century many attempts have been performed to

Hadi Savaloni

savaloni@khayam.ut.ac.ir

1 Department of Physics, University of Tehran, North-Kargar Street, Tehran, Iran

2 Department of Physics, Islamic Azad University, Science and Research Branch, Tehran, Iran improve methods with high efficiency for corrosion protection of metals in different atmospheres and media.

Variation of the ratio of different elements in the structure of stainless steels results in different corrosion behavior in each corroding medium [1,2].

The higher concentration of Mo and Ni in AISI316L stainless steels (SS316L) increases the grooving and pitting-type corrosions of this material. AISI 316 and AISI 316L exhibit high expansion property against heat treatment as well as high resistance against mechanical pressures. AISI316L consists of less carbon in its structure relative to AISI316. This leads to lower sensitivity of the alloy against sensitization effect which appears at higher temperatures treatments of this material. Carbide precipitation due to a welding process or heat treatment can cause the occurrence of chromium-depleted zones at the grain boundaries, leading to a phenomenon known as sensitization, in which the depleted zones become the focus of the intense corrosion [3, 4].

Due to the higher corrosion resistance of stainless steels than other alloys and its low price, in addition their activepassive behavior in corroding environments, now stainless steels are widely applied in both industrial and commercial applications such as oil and gas industry, offshore platforms, nuclear reactors, aerospace, among many others $[5,6]$.

The most effective austenite stabilizers are $\mathrm{Ni}, \mathrm{Mn}, \mathrm{N}, \mathrm{C}$ and $\mathrm{Cu}$ among which $\mathrm{C}, \mathrm{Ni}$ and $\mathrm{Mn}$ are the most important ones. Nickel content plays an important role in the stability of austenitic structure at high temperatures hence highnickel alloys provide good resistance to a wide variety of corrosive media and improves the physical and mechanical properties of stainless steel [7-9]. Manganese because of having lower cost is a good candidate to replace nickel as an austenite stabilizing element [10-15]. Manganese also increases the solubility of nitrogen [16]. 
So far, to the best of knowledge at the time of submission of this manuscript, different metal oxide coatings have been studied in respect of corrosion resistance, but the corrosion resistance properties of manganese oxide thin films as a coating on stainless steel has not been investigated by potentiodynamic method and these films have been only studied in respect of other properties such as electrical and optical properties. Accordingly, in this work to improve the corrosion resistance of stainless steel in $\mathrm{NaCl}$ solutions with different concentrations, it was decided to make use of the useful properties of manganese oxide on SS316L. This was implemented by a combination of e-beam deposition of $\mathrm{Mn}$ on stainless steels and subsequent annealing of the samples with flow of oxygen at $673 \mathrm{~K}$ temperatures. The corrosion behavior of the produced samples was investigated in $\mathrm{NaCl}$ solution with different concentrations using both potentiodynamic and electrochemical impedance spectroscopy (EIS) techniques. A correlation between the structural characteristics of the samples and their corrosion inhibition behavior is obtained.

\section{Experimental details}

Manganese (99.98 \% in purity) films of $300 \mathrm{~nm}$ were deposited on the type $316 \mathrm{~L}$ stainless steel substrates $(18 \times 18 \times 1 \mathrm{~mm})$ with a deposition rate of $0.8 \AA / \mathrm{s}$. An electron gun was used for the evaporation of Mn which took place at room temperature. An Edwards (Edwards E19 A3) coating plant with a base pressure of $2 \times 10^{-7} \mathrm{mbar}$ was used. The chemical composition of the stainless steels used in this work was obtained using both X-ray fluorescence (XRF) and carbon analyses methods and the results are given in Table 1.

The stainless steel substrates/plates were covered with a polyethylene sheet (as a protective medium against scratching and oxidation) by the production factory. After cutting the substrates to the desired size, the polyethylene sheet was removed by soaking the substrates in ethanol and prior to deposition all substrates were ultrasonically cleaned in heated acetone and then ethanol. No mechanical polishing or any other disturbance was applied on the produced steels by the production factory and their surface roughness was measured as received materials. The substrate holder was a disk of $17 \mathrm{~cm}$ in diameter with 8 circular holes of $2.5 \mathrm{~cm}$ diameter for the insertion/fixation of substrates, which their centers were at a distance of $6.5 \mathrm{~cm}$ from the center of the disk. The distance between the center of the evaporation crucible and the substrate holder disk was $26.5 \mathrm{~cm}$. Therefore, the substrates normal to the direction of incidence of the evaporant beam was at $14^{\circ}$. In each run, we produced eight of $\mathrm{Mn} /(\mathrm{SS} 316 \mathrm{~L})$ films. Since small crucibles are used in this experiment (6 $\mathrm{mm}$ in diameter) they can be considered as point sources and it can be assumed that it should provide similar evaporation condition (flux) to all eight substrates that the same thickness can be obtained in all substrates in each run, which can be used for different analysis. The deposition process was repeated several times and the samples which were used at different stages of this work produced consistent results within the logical experimental achievements at each stage. The film thickness was controlled by a quartz crystal deposition rate controller (Sigma instrument, SQM-160, USA) positioned close to the substrates.

Post-annealing of Mn/(SS316L) samples was performed at $673 \mathrm{~K}$ temperature in oxygen environment with a flow rate of $250 \mathrm{sccm}$, using a cylindrical horizontal quartz tube furnace (Exciton, 1200-30/6, T.H, Iran equipped to Shinko temperature programmable controller-PCD 33A). The annealing procedure took place in three steps as: (1) $35 \mathrm{~min}$ in steps of $7{ }^{\circ} \mathrm{C}$ per minute to reach the set annealing temperature, (2) samples were kept at pre-set annealing temperature for $4 \mathrm{~h}$, (3) about $4 \mathrm{~h}$ cooling temperature. The cooling procedure of the samples took place inside the quartz tube of the furnace with the same flow of oxygen used during annealing.

Crystallographic structure of these films was obtained using a Philips XRD X'pert diffractometer $\left(\mathrm{CuK}_{\alpha}\right.$ radiation) with a step size of $0.02^{\circ}$, count time of $1.0 \mathrm{~s}$ per step, an acceleration voltage of $40 \mathrm{kV}$ and current of $40 \mathrm{~mA}$, while the surface physical morphology/nanostructure and roughness was obtained by means of AFM (Nt-mdt scanning probe microscope, BL022, Russia; with low-stress silicon nitride tip of less than $200 \AA$ radius and tip opening

Table 1 Chemical composition and abundances (\%) of different elements in 316L stainless steel

\begin{tabular}{|c|c|c|c|c|c|c|c|c|c|c|c|c|c|c|c|c|c|c|}
\hline \multirow{3}{*}{$\begin{array}{l}\text { AISI } \\
316 \mathrm{~L} \\
\text { stainless } \\
\text { steel }\end{array}$} & $\begin{array}{l}\text { Element } \\
\text { (Wt \%) }\end{array}$ & & & & & & & & & & & & & & & & & \\
\hline & V & $\mathrm{Cr}$ & $\mathrm{Mg}$ & $\mathrm{K}$ & $\mathrm{Na}$ & $\mathrm{Ca}$ & $\mathrm{Fe}$ & $\mathrm{Al}$ & $\mathrm{Si}$ & $\mathrm{C}$ & $\mathrm{S}$ & $\mathrm{P}$ & $\mathrm{Mn}$ & $\mathrm{Ti}$ & Mo & $\mathrm{Cu}$ & $\mathrm{Ni}$ & $\mathrm{Co}$ \\
\hline & 0.092 & 17.25 & 0.01 & 0.02 & 0.01 & 0.02 & 72.01 & 0.15 & 0.56 & 0.03 & 0.11 & 0.11 & 1.042 & 0.01 & 0.11 & 0.132 & 8.310 & 0.18 \\
\hline
\end{tabular}


of $18^{\circ}$ ) analysis and scanning electron microscope (SEM: LEO 440i, England). Root mean square (rms) and average surface roughness as well as average grain size of the samples were obtained from the 2D AFM images using Nova and JMicroVision Codes, respectively.

The electrochemical test of the samples was performed using potentiodynamic method with a potentiostat coupled to PC (IVIUM-Compact-state, 20250). To carry out this analysis only an area of $1.0 \pm 0.05 \mathrm{~cm}^{2}$ was exposed to the $\mathrm{NaCl}$ corroding medium. The rest of surface area and back and edges of the sample were coated with a thick resin of lacquer paint. The samples were polarized in a $0.3,0.5$ and $0.6 \mathrm{M} \mathrm{NaCl}$ solution made of analytical-grade reagent and double-distilled water. The samples were fixed inside an inert mounting fixture (polyamide). This allowed an electrical contact to be supplied to the sample, without being influenced by undesirable effects on the working electrode. The polarization potential was applied via a copper wire contacted on the back side of the sample in the fixture, while an $\mathrm{Ag} / \mathrm{AgCl}$ reference electrode and a platinum counter electrode were used in a three electrode setup. The potential sweep rate was $1 \mathrm{mV} \mathrm{s}^{-1}$, and was scanned for each sample starting from $-1.0 \mathrm{~V}$ vs. open circuit potential $\left(V_{\text {ocp }}\right)$. The ends of the scans were selected after considering transpassive behavior in polarization curves $(\sim 1.0 \mathrm{~V})$. All of the potentials presented in this work are as a function of $\mathrm{Ag} / \mathrm{AgCl}$. All measurements were performed at $298 \mathrm{~K}$. An initial delay of $45 \mathrm{~min}$ for the samples to reach a steady-state condition was considered before polarization test.

The corrosion current density $j_{\text {corr }}$ and the corrosion potential $E_{\text {corr }}$ were calculated from the Tafel extrapolation of polarization curves of semi-logarithmic plot using the method prescribed in [17].

The electrochemical impedance spectroscopy (EIS) measurements were also performed using above-mentioned cell used for corrosion test and the equipments used in the polarization test. Impedance values were recorded in the frequency range of $100 \mathrm{kHz}-100 \mathrm{mHz}$. The voltage amplitude was $1 \mathrm{mV}$ with respect to the open circuit potential. The analysis of the impedance spectra was performed using Zview software and the equivalent circuit fitted to the experimental data was obtained.

\section{Results and discussions}

\section{Crystallographic and nanostructure of the films}

Figure 1 shows the XRD patterns of the bare SS316L substrate, as-deposited $\mathrm{Mn} / \mathrm{SS}(316 \mathrm{~L})$ and the post-annealed $\mathrm{Mn} /(\mathrm{SS} 316 \mathrm{~L})$ films with flow of oxygen $\left(250 \mathrm{~cm}^{3} /\right.$ $\min )$ at $673 \mathrm{~K}$ temperature, respectively. The diffraction

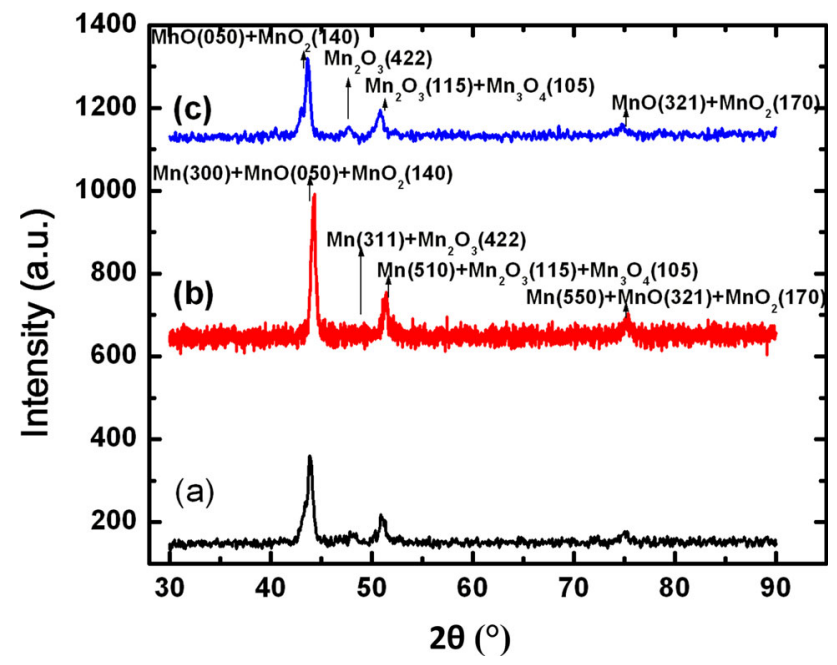

Fig. 1 XRD Patterns of 316L stainless steel, Mn/(SS316L) and Mn/ (SS316L) sample annealed at $673 \mathrm{~K}$ temperature with flow of oxygen

pattern of the as-deposited Mn/(SS316L) film (Fig. 1b), in addition to three SS peaks [austenite peaks $\gamma$-Fe(lllll), $\gamma$ $\operatorname{Fe}(2 \quad 0 \quad 0)$ and $\gamma-\operatorname{Fe}(2 \quad 2 \quad 0)]$ (Fig. 1a) shows that the intensity of the first peak is almost doubled while the width of this peak is also decreased. This observation as well as the information obtained from the JCPDS cards (00-001-1234; 00-004-0326; 00-007-0222; 00-003-1001; 00-002-0902; 00-003-0991; 00-006-0540; 00-0021062;00-001-1237) indicates that this peak can possibly be assigned as a combination of $\mathrm{Mn}(300)+\mathrm{MnO}(050)+$ $\mathrm{MnO}_{2}(140)$. The second and the third peaks are also changed almost in the same way but with less strength. They can also be assigned as combination of $\mathrm{Mn}$ and manganese oxide diffracting lines as shown on Fig. 1. Hence, it can be deduced that $\mathrm{Mn}$ film is formed on the stainless substrate and the formation of oxides can be related to the presence of oxygen in the deposition chamber. The XRD pattern of the annealed sample (Fig. 1c) clearly shows the formation of manganese oxide diffraction lines according to the JCPDS cards (00-0070222; 00-004-0326; 00-002-0902; 00-006-0540; 00-0021062) as assigned in Fig. 1.

In Fig. 2a-c, 2D and 3D AFM images of bare stainless steel, as-deposited $\mathrm{Mn} /(\mathrm{SS} 316 \mathrm{~L})$ and post-annealed Mn/ (SS316L) with a flow of oxygen $\left(250 \mathrm{~cm}^{3} / \mathrm{min}\right)$ at $673 \mathrm{~K}$ temperature are given, respectively. The surface roughness (root mean square and average) obtained from the AFM analysis is given in Table 2. Results show that the surface roughness is increased by deposition of $\mathrm{Mn}$ and annealing process. The AFM image of bare SS316L shows large grains with deep valleys between them while by deposition of $300 \mathrm{~nm} \mathrm{Mn}$ on this surface the morphology is totally changed and almost homogeneous surface but with a large hump is formed. This may be 
Fig. 2 2D and 3D AFM images of (a) AISI 316L stainless steel, b $\mathrm{Mn} /(\mathrm{SS} 316 \mathrm{~L})$, c Mn/

(SS316L) sample annealed at $673 \mathrm{~K}$ temperature with flow of oxygen
(I)

(a)

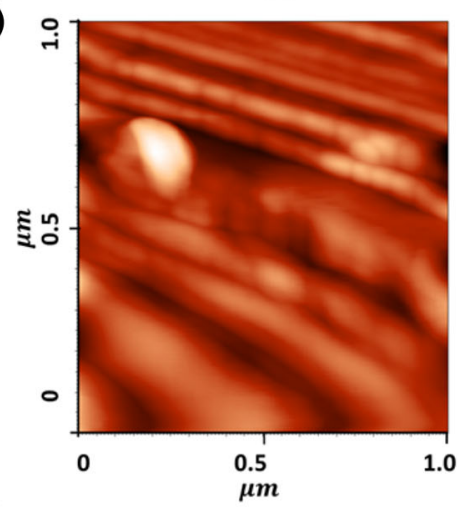

(b)

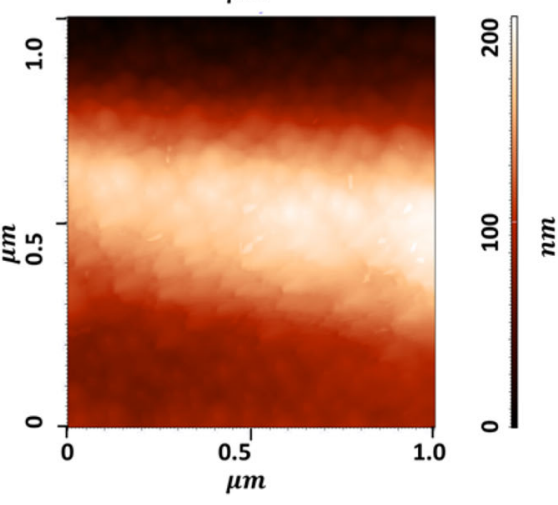

(c)

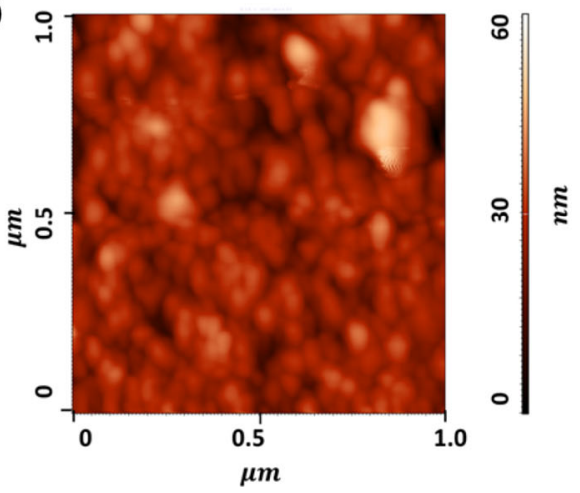

(II)
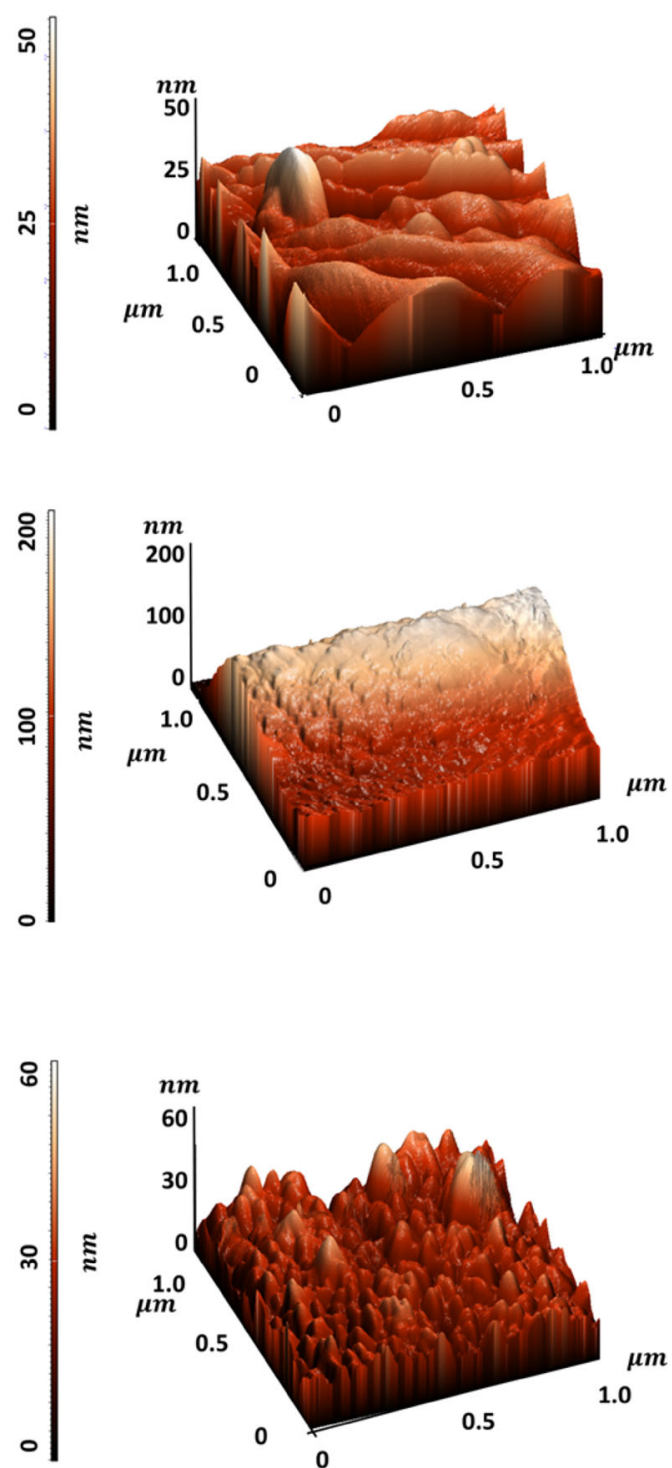

Table 2 The grain size, rms roughness of $316 \mathrm{~L}$ stainless steel and $\mathrm{Mn} /(\mathrm{SS} 316 \mathrm{~L})$ samples annealed at $673 \mathrm{~K}$

\begin{tabular}{lll}
\hline Sample & Rms $(\mathrm{nm})$ & $R$ average $(\mathrm{nm})$ \\
\hline AISI 316 SS & 20.7 & - \\
Mn/ AISI 316 & 51.0 & 55.8 \\
Mn/ AISI 316 & 65.7 & 68.1 \\
Annealed at 673K & & \\
\hline
\end{tabular}

different on a larger scale image and again may be different on a different area of the sample. However, by annealing this sample with flow of oxygen a needle-like surface (narrow columns) is formed. During annealing two different process may take place as (1) diffusion due to increased temperature which induces energy in the adatoms on the surface hence increased mobility. Therefore, one may expect coalescence of the grains. (2) Penetration of oxygen atoms/ions inside the bulk of the grains/surface. Khojier and Savaloni [18] reported that this process leads to the breakdown of the grains and results in the formation of smaller (needle-like) grains. The observed result in this figure shows that the latter process has been the dominant one as the XRD results of this film in Fig. 1 also confirm the formation of oxide film. 


\section{Polarization results}

Potentiodynamic curves for the bare SS316L stainless steel substrate and post-annealed $\mathrm{Mn} /(\mathrm{SS} 316 \mathrm{~L})$ with a flow of oxygen $\left(250 \mathrm{~cm}^{3} / \mathrm{min}\right)$ at $673 \mathrm{~K}$ temperature in $\mathrm{NaCl}$ corroding media with different concentrations, namely $0.3 \mathrm{M}$ $\mathrm{NaCl}, 0.5 \mathrm{M} \mathrm{NaCl}$ and $0.6 \mathrm{M} \mathrm{NaCl}$, are compared in Fig. 3a-c, respectively. It can be observed that all these curves show active-passive behavior. Table 3 gives the electrochemical characteristics obtained from these curves using Corrview software. In the polarization curves, the corrosion current is related to the kinetics or corrosion rate and the corrosion potential is corresponding to the thermodynamics or the tendency to the corrosion which is dependent on the experimental conditions. Results show that the process of annealing of $\mathrm{Mn} /(\mathrm{SS} 316 \mathrm{~L})$ samples enhances the corrosion resistance of the samples relative to the bare stainless steel. However, the increase of $\mathrm{NaCl}$ concentration in the corroding medium from 0.3 to $0.5 \mathrm{M}$ has reduced this resistance by half and also increase of this concentration to $0.6 \mathrm{M}$ has reduced the corrosion resistance to less than half relative to $0.5 \mathrm{M}$ concentration (Fig. 4).
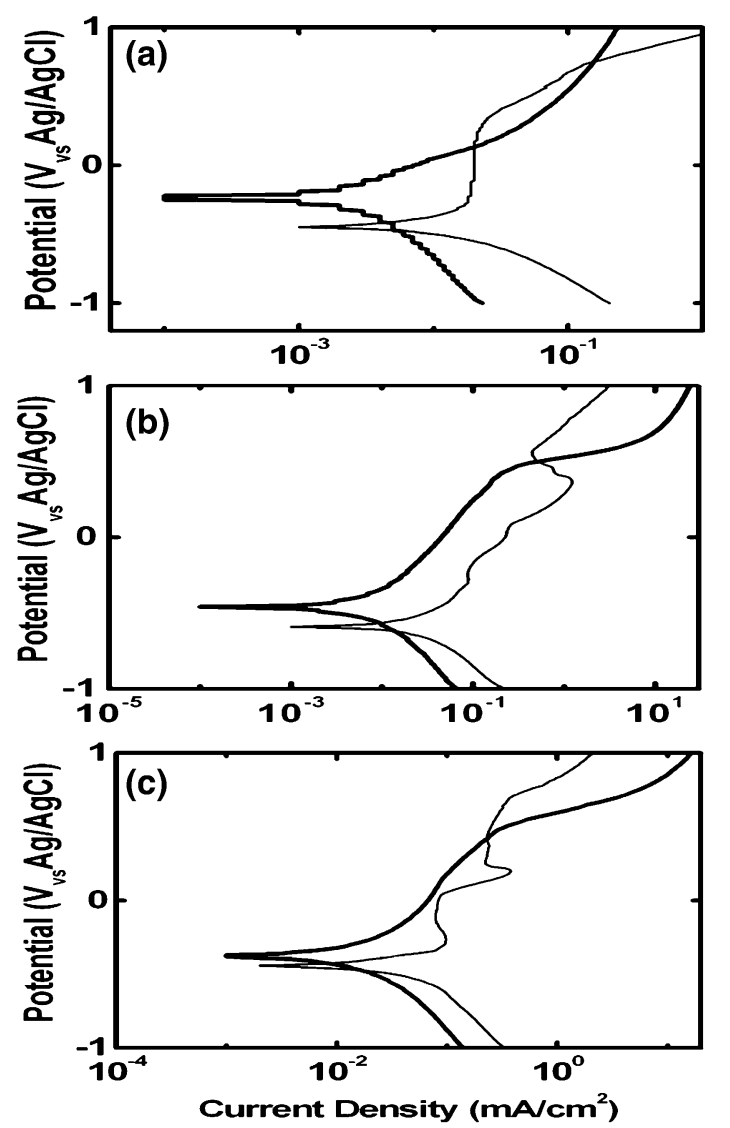

Fig. 3 Potentiodynamic polarization curves for (a) AISI $316 \mathrm{~L}$ stainless steel, b Mn/(SS316L), c Mn/(SS316L) sample annealed at $673 \mathrm{~K}$ temperature with flow of oxygen
This shows that corrosion inhibition in this type of examination is a linear function of concentration of the corroding agent with a negative slope which fits to a linear function as $Y=A+\mathrm{BX}$ (Fig. 5).

The impedance spectroscopy of the samples was carried out to determine the complex frequency-dependent impedance $Z(\omega)=Z^{\prime}+i Z^{\prime \prime}(\omega)$, of all samples. Plotting for a simple RC circuit, the negative imaginary part of $Z(\omega)$, $-\operatorname{Im} Z(\omega)$, as a function of the real part, $\operatorname{Re} Z(\omega)$, would usually result in semicircle with a diameter $R$ (Nyquist plot [19]) and its center at the $\operatorname{Re} Z(\omega)$ axis, at a distance of $R / 2$ from the origin. The presence of any additional resistance $R_{c}$ due to contacts will shift the center of the semicircle by $R_{c}$ to higher values. The diameter of such semicircle will provide the value for $R$ and the value of $C$ can be obtained

Table 3 Polarization parameters of 316L stainless steel and $\mathrm{Mn} /$ (SS316L) samples annealed at $673 \mathrm{~K}$

\begin{tabular}{|c|c|c|}
\hline Sample & $\begin{array}{l}\text { Corrosion potential } \\
\text { (Vvs. } \mathrm{Ag} / \mathrm{AgCl})\end{array}$ & $\begin{array}{l}\text { Corrosion current } \\
\text { density }\left(\mathrm{mA} / \mathrm{cm}^{2}\right)\end{array}$ \\
\hline $\begin{array}{l}\text { AISI 316SS In } \\
0.3 \mathrm{M} \mathrm{NaCl}\end{array}$ & -0.40 & 0.019 \\
\hline $\begin{array}{l}\mathrm{Mn} / \text { AISI } 316 \text { In } \\
0.3 \mathrm{M} \mathrm{NaCl}\end{array}$ & -0.24 & 0.002 \\
\hline $\begin{array}{l}\text { AISI } 316 \text { SS In } \\
0.5 \mathrm{M} \mathrm{NaCl}\end{array}$ & -0.59 & 0.033 \\
\hline $\begin{array}{c}\mathrm{Mn} / \mathrm{AISI} 316 \mathrm{In} \\
0.5 \mathrm{M} \mathrm{NaCl}\end{array}$ & -0.47 & 0.006 \\
\hline $\begin{array}{l}\text { AISI } 316 \mathrm{SS} \text { In } \\
0.6 \mathrm{M} \mathrm{NaCl}\end{array}$ & -0.43 & 0.062 \\
\hline $\begin{array}{l}\mathrm{Mn} / \mathrm{AISI} 316 \mathrm{In} \\
0.6 \mathrm{M} \mathrm{NaCl}\end{array}$ & -0.38 & 0.030 \\
\hline
\end{tabular}

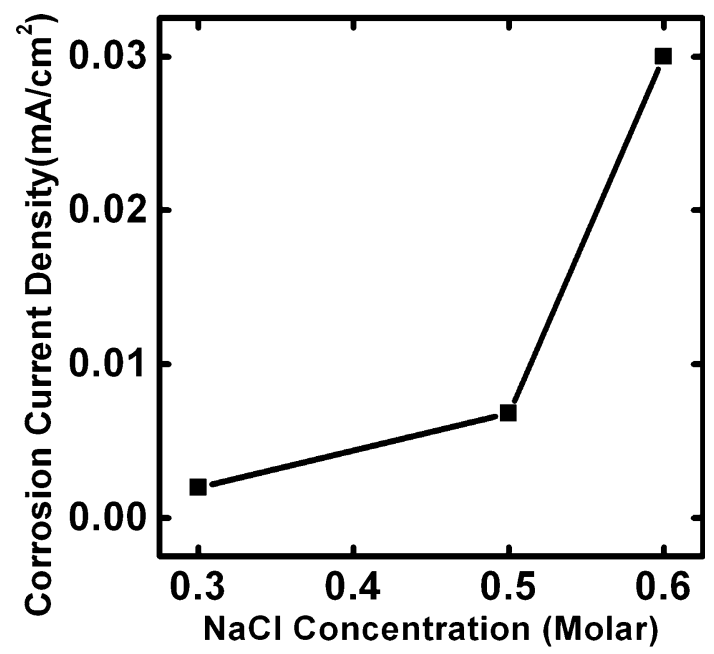

Fig. 4 Variation of corrosion current density versus $\mathrm{NaCl}$ concentration (corroding medium) for $\mathrm{Mn} /(\mathrm{SS} 316 \mathrm{~L})$ sample annealed at $673 \mathrm{~K}$ temperature with flow of oxygen 


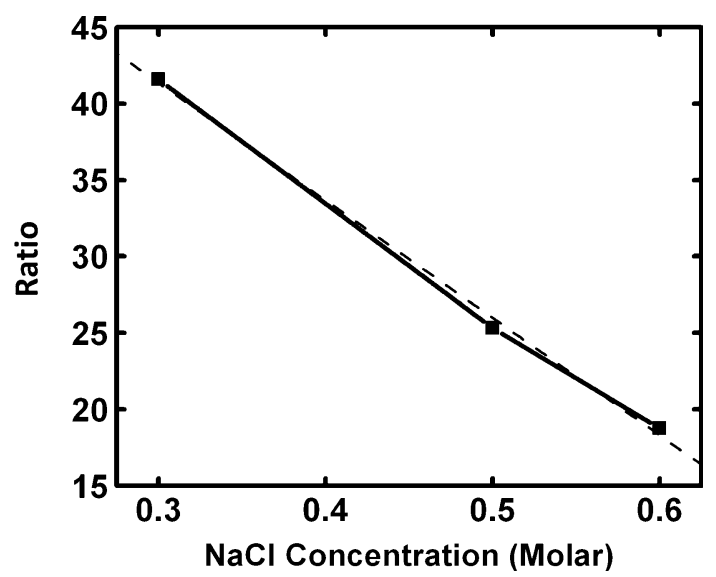

Fig. 5 Variation of ratio of corrosion resistance of $\mathrm{Mn} /(\mathrm{SS} 316 \mathrm{~L})$ sample annealed at $673 \mathrm{~K}$ temperature with flow of oxygen to the bare $\mathrm{SS} 316 \mathrm{~L}$ versus $\mathrm{NaCl}$ concentration (corroding medium) from the relation $C=\frac{1}{\left(R \omega_{a}\right)}$, where $R \omega_{a}$ is the value of $\omega$ at the apex of the semicircle.

In Fig. 6a columns I, II and III, the Nyquist plots of bare SS316Ls are compared with those of post-annealed $\mathrm{Mn} /$ (SS316L)s with a flow of oxygen $\left(250 \mathrm{~cm}^{3} / \mathrm{min}\right)$ at $673 \mathrm{~K}$ temperature in different corroding media, namely $0.3 \mathrm{M}$ $\mathrm{NaCl}, 0.5 \mathrm{M} \mathrm{NaCl}$ and $0.6 \mathrm{M} \mathrm{NaCl}$, respectively.

Each sample was left in the corroding medium for $1 \mathrm{~h}$ before taking measurements for the Nyquist plot. In Fig. 6b, c columns I, II amd III, the corresponding Bode and phase diagrams of these samples are given. All of the Bode diagrams in Fig. 6b show two time constants (at high and low frequencies). This effect is usually observed for composite films consisting of a dense internal layer (bottom layer) and a less compact (porous) outer layer. Considering this observation, an equivalent circuit was
Fig. 6 a Experimental Nyquist diagrams, b Bode diagrams, c Phase diagrams for; column I AISI 316L stainless steel, column II Mn/(SS316L), column III $\mathrm{Mn} /(\mathrm{SS} 316 \mathrm{~L})$ sample annealed at $673 \mathrm{~K}$ temperature with flow of oxygen
(I)
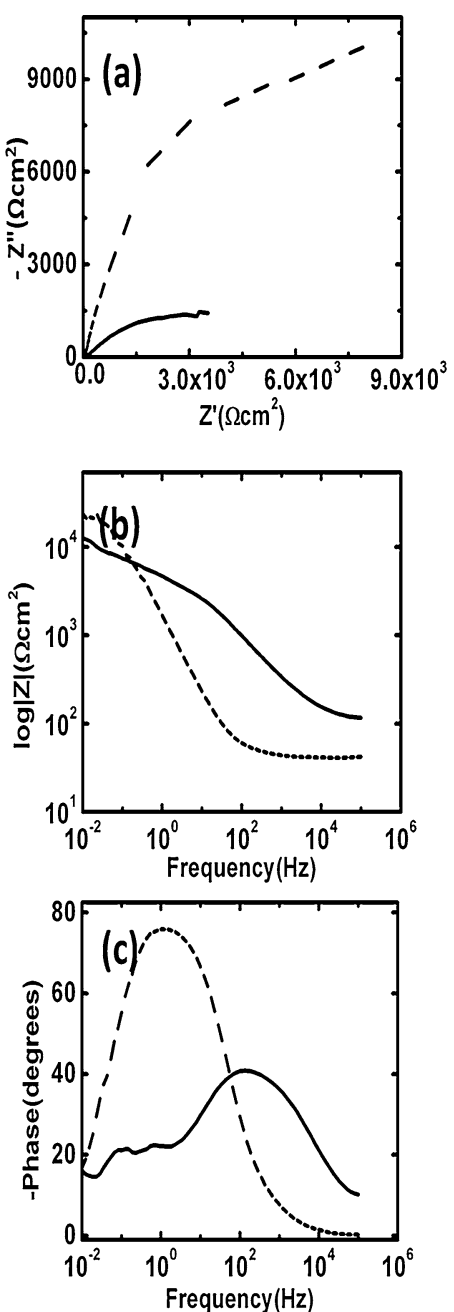

(II)
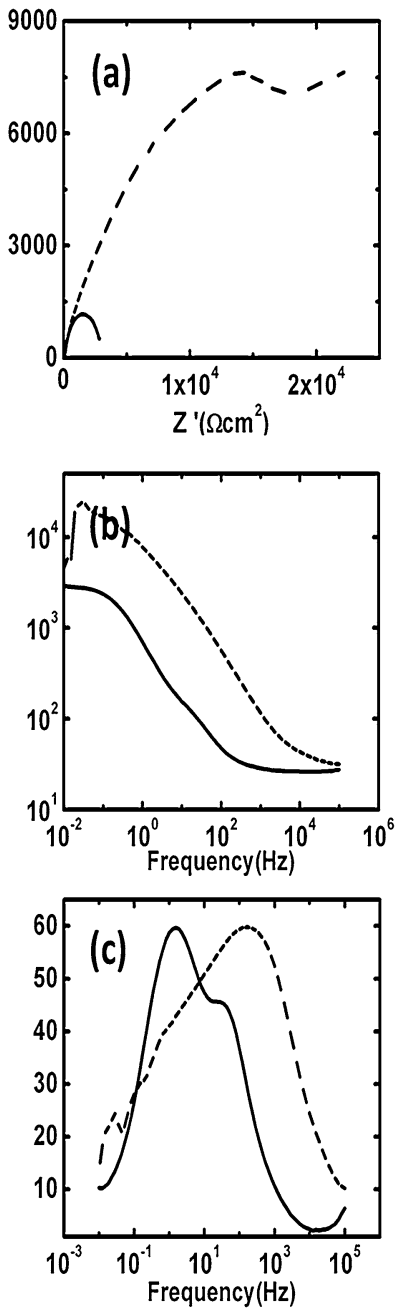

(III)
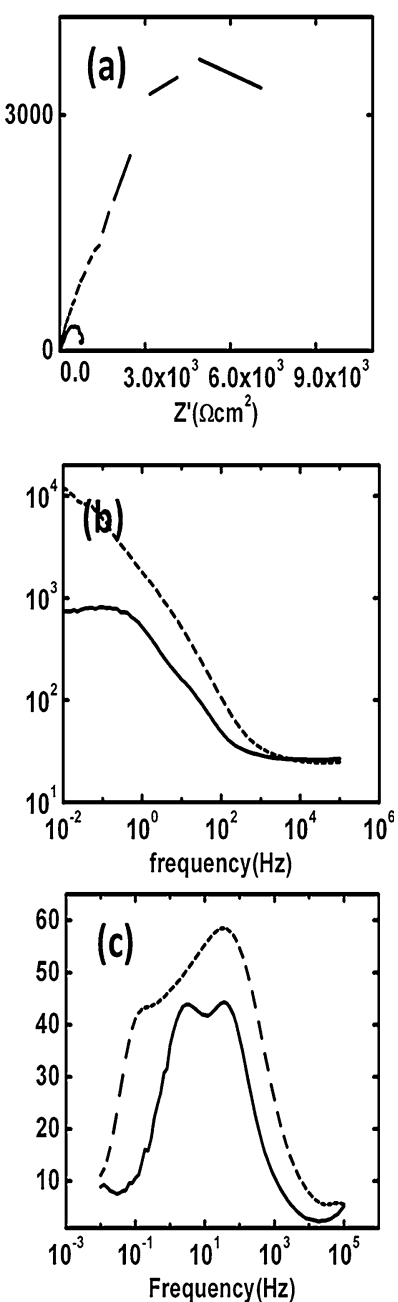


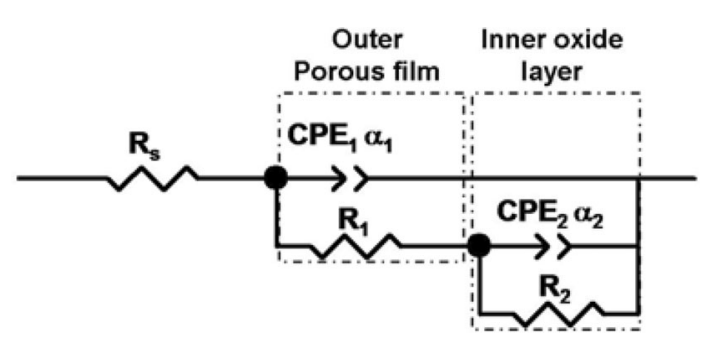

Fig. 7 Electrical equivalent circuit obtained for AISI 316L stainless steel, $\mathrm{Mn} /(\mathrm{SS} 316 \mathrm{~L})$ and $\mathrm{Mn} /(\mathrm{SS} 316 \mathrm{~L})$ sample annealed at $673 \mathrm{~K}$ temperature with flow of oxygen

designed to simulate the results. In all spectra, the absolute value of the maximum phase angle is less than 90 degree. Hence, we require a constant phase element (CPE). The impedance can be obtained from:

$Z_{\mathrm{CPE}}=\frac{1}{Q(j w)^{\alpha}}$

where $Q$ is the constant of $\mathrm{CPE}, \mathrm{w}$ is the angular frequency $(\mathrm{rad} / \mathrm{s}), j^{2}=-1$ is the imaginary number and $\alpha$ is the CPE exponent. Based on the value of $\alpha$ three different types of CPE state may occur as; resistance $\left(\alpha=0, Z_{0}=R\right)$; capacitance $\left(\alpha=1, \quad Z_{0}=C\right)$; Warburg impedance $\left(\alpha=0.5, Z_{0}=W\right)$. The elements of CPE are converted to a net capacitance which can be calculated as:

$C=\frac{(Q \cdot R)^{1 / \alpha}}{R}$

Figure 7 shows the equivalent circuit used to simulate the EIS data for all samples.

In Fig. 7 two capacitors as CPE1 and CPE2 are included. CPE1 is the capacitance of the interface of substrate coating, and CPE2 is the coating capacitance observed for coatings that the solution penetrates in their structures due to presence of different defects or porosity. The physical
(I)
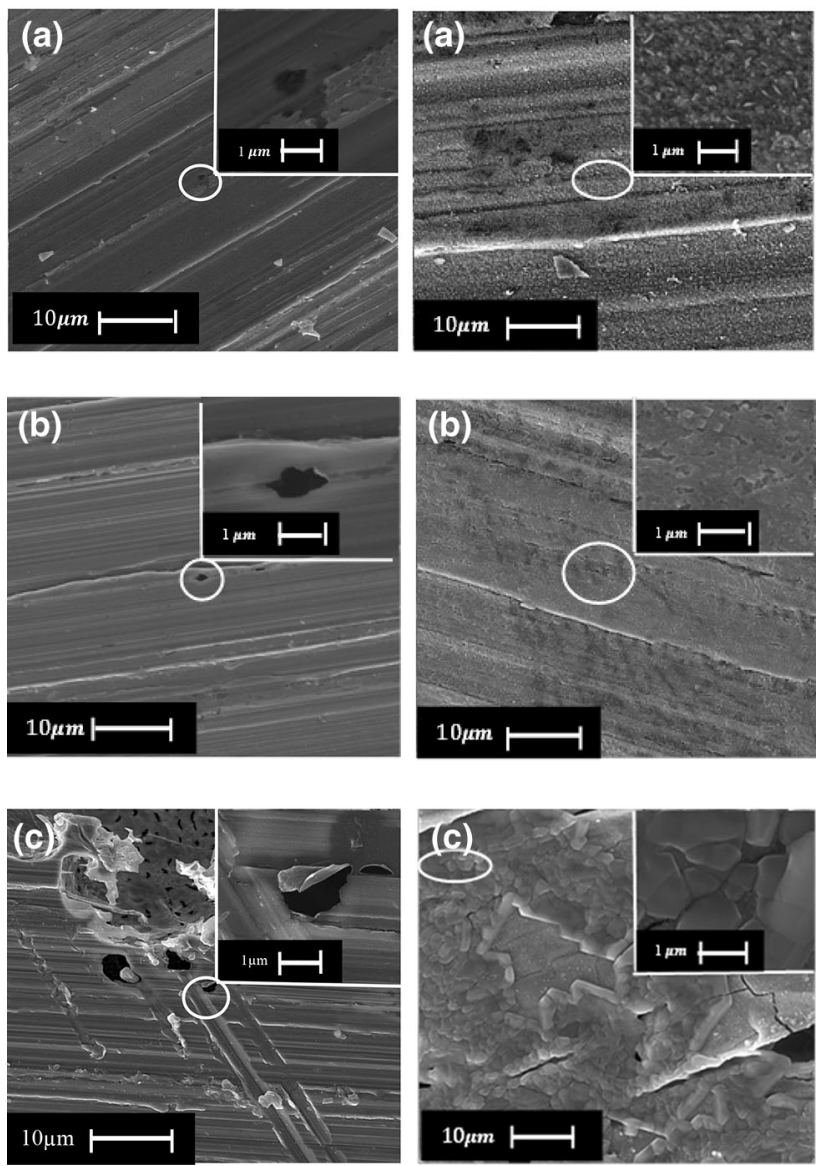

Fig. 8 SEM images of (a) AISI 316L stainless steel, b Mn/(SS316L), c $\mathrm{Mn} /(\mathrm{SS} 316 \mathrm{~L})$ sample annealed at $673 \mathrm{~K}$ temperature with flow of oxygen

description of the simulated work is that $R_{1}, C_{1}$ and $R_{2}, C_{2}$ refer to the resistance and capacitance of the outer porous and inner oxide layers. The electrical parameters obtained

Table 4 Electrochemical impedance spectroscopy parameters of 316L stainless steel and Mn/(SS316L) samples annealed at $673 \mathrm{~K}$

\begin{tabular}{|c|c|c|c|c|c|c|c|c|c|c|}
\hline Sample & $\begin{array}{l}R_{\mathrm{s}} \\
\left(\mathrm{K} \Omega \mathrm{cm}^{2}\right)\end{array}$ & $\begin{array}{l}R_{1} \\
\left(\mathrm{~K} \Omega \mathrm{cm}^{2}\right)\end{array}$ & $\alpha_{1}$ & $\begin{array}{l}Q_{1} \\
\left(\mu \mathrm{F} \mathrm{cm}^{-2}\right)\end{array}$ & $\begin{array}{l}C_{1} \\
\left(\mu \mathrm{F} \mathrm{cm}^{-2}\right)\end{array}$ & $\begin{array}{l}R_{2} \\
\left(\mathrm{~K} \Omega \mathrm{cm}^{2}\right)\end{array}$ & $\alpha_{2}$ & $\begin{array}{l}Q_{2} \\
\left(\mu \mathrm{F} \mathrm{cm}^{-2}\right)\end{array}$ & $\begin{array}{l}C_{2} \\
\left(\mu \mathrm{F} \mathrm{cm}^{-2}\right)\end{array}$ & $\begin{array}{l}\mathrm{RP} \\
\left(\mathrm{K} \Omega \mathrm{cm}^{2}\right)\end{array}$ \\
\hline $\begin{array}{l}\text { AISI } 316 \text { SS In } 0.3 \mathrm{M} \\
\mathrm{NaCl}\end{array}$ & 0.090 & 10.865 & 0.470 & 87.0 & 197210 & 1.401 & 0.729 & 19 & 64.35 & 12.266 \\
\hline $\begin{array}{l}\mathrm{Mn} / \mathrm{AISI} 316 \text { In } 0.3 \mathrm{M} \\
\mathrm{NaCl}\end{array}$ & 0.040 & 41.572 & 0.888 & 119.9 & 350.90 & 0.008 & 0.765 & 329 & 444.13 & 41.580 \\
\hline $\begin{array}{l}\text { AISI } 316 \text { SS In } 0.5 \mathrm{M} \\
\mathrm{NaCl}\end{array}$ & 0.026 & 2.744 & 0.893 & 285.0 & 633.16 & 0.094 & 0.790 & 264 & 620.47 & 2.838 \\
\hline $\begin{array}{l}\mathrm{Mn} / \mathrm{AISI} 316 \text { In } 0.5 \mathrm{M} \\
\mathrm{NaCl}\end{array}$ & 0.031 & 23.261 & 0.766 & 25.2 & 176.59 & 2.049 & 0.707 & 382 & 6045 & 25.310 \\
\hline $\begin{array}{l}\text { AISI } 316 \text { SS In } 0.6 \mathrm{M} \\
\mathrm{NaCl}\end{array}$ & 0.026 & 0.723 & 0.797 & 218.0 & 791.01 & 0.122 & 0.896 & 347 & 535.80 & 0.845 \\
\hline $\begin{array}{l}\mathrm{Mn} / \mathrm{AISI} 316 \text { In } 0.6 \mathrm{M} \\
\mathrm{NaCl}\end{array}$ & 0.024 & 17.652 & 0.755 & 249.0 & 3787.02 & 1.201 & 0.769 & 113 & 493.27 & 18.852 \\
\hline
\end{tabular}


by implementing the above procedure to the experimental results are given in Table 4 for different samples produced and tested in this work.

\section{SEM results}

To observe how the samples are affected in the corroding media, after completion of the potentiodynamic test, SEM analysis was performed. Figure $8 \mathrm{a}-\mathrm{c}$ columns I and II show the SEM images of bare SS316L and Mn/(SS316L) samples annealed with flow of oxygen after corrosion test in $\mathrm{NaCl}$ corroding mediums with different concentrations. From the comparison of the SEM images in Fig. 8, it can be concluded that the coated samples with $\mathrm{Mn}$ film and annealed with flow of oxygen in all cases (i.e., in different concentration of $\mathrm{NaCl}$ solutions) show less damaged surfaces while the lower the $\mathrm{NaCl}$ concentration the higher corrosion resistance is obtained consistent with the polarization and EIS results.

\section{Conclusions}

Manganese films of $300 \mathrm{~nm}$ thickness were coated on $316 \mathrm{~L}$ types of stainless steel, then they were annealed with a flow of oxygen $\left(250 \mathrm{~cm}^{3} / \mathrm{min}\right)$ at $673 \mathrm{~K}$ temperature.

The results of potentiodynamic test which were carried out in $\mathrm{NaCl}$ solution with different concentrations showed that the corrosion resistance of all coated samples in different corroding media is improved relative to the bare samples. In addition, as expected, increase of $\mathrm{NaCl}$ concentration decreased the corrosion inhibition and this decrease is a linear function with a negative slope.

The nanostructure and crystallography of the samples were analyzed using XRD and AFM before corrosion test and SEM after corrosion test. The AFM results showed that initially oxygen atoms/ions penetrate inside the bulk of the grains/surface and cause breakdown of the grains which leads to formation of smaller (needle-like) grains. The relationship between the structural changes in the samples and the corrosion results is discussed and correlation is obtained.

Acknowledgments This work was carried out with the support of the University of Tehran, Azad University and the Iran National Science Foundation (INSF). HS is grateful to the Centre of Excellence for Physics of Structure and Microscopic Properties of Matter, Department of Physics, University of Tehran for partial support of this work.

Open Access This article is distributed under the terms of the Creative Commons Attribution 4.0 International License (http://crea tivecommons.org/licenses/by/4.0/), which permits unrestricted use, distribution, and reproduction in any medium, provided you give appropriate credit to the original author(s) and the source, provide a link to the Creative Commons license, and indicate if changes were made.

\section{References}

1. Haitao, W., Qi, Z., Huashun, Y., Zhenya, Z., Hongwei, C., Guanghui, M.: Effect of aluminium and silicon on high temperature oxidation resistance of $\mathrm{Fe}-\mathrm{Cr}-\mathrm{Ni}$ heat resistant steel. Trans. Tianjin Univ. 15, 457-462 (2009)

2. Alvarez-Armas, I.: Duplex stainless steels: brief history and recent alloys. Recent Patents Mech. Eng. 1, 51-57 (2008)

3. Atanda, P., Fatudimu, A., Oluwole, O.: Sensitisation study of normalized 316L stainless steel. J. Miner. Mater. Char. Eng. 9(1), 13-23 (2010)

4. Grayeli-Koroi, A., Savaloni, H., Habibi, M.: Corrosion inhibition of stainless steel type AISI 304 by Mn coating and subsequent annealing with flow of nitrogen at different temperatures. Appl. Surf. Sci. 276, 269-275 (2013)

5. Baddoo, N.R.: Stainless steel in construction: a review of research, applications, challenges and opportunities. J. Constr. Steel Res. 64, 1199-1206 (2008)

6. Gooch, T.G.: TWI, Welding new stainless steels for the oil and gas industry. NACE International, pp. 26-31 (2000)

7. Revie, R.W., Uhlig, H.H.: Corrosion and corosion control, pp. 407-418. Wiley Interscience, New Jersey (2008)

8. Potgieter, J.H., Olubambi, P.A., Cornish, L., Machio, C.N., Sherif, E.-S.M.: Influence of nickel additions on the corrosion behaviour of low nitrogen $22 \% \mathrm{Cr}$ series duplex stainless steels. Corros. Sci. 50(9), 2572-2579 (2008)

9. Bautista, A., Blanco, G., Velasco, F.: Corrosion behaviour of low-nickel austenitic stainless steels reinforcements: a comparative study in simulated pore solutions. Cem. Concr. Res. 36, 1922-1930 (2006)

10. Kappaganthu, S.R., Sun, Y.: Formation of an MN-type cubic nitride phase in reactively sputtered stainless steel-nitrogen films. J. Cryst. Growth 267, 385-393 (2004)

11. Merello, R., Botana, F.J., Botella, J., Matres, M.V., Marcos, M.: Influence of chemical composition on the pitting corrosion resistance of non-standard low-Ni high-Mn-N duplex stainless steels. Corros. Sci. 45, 909-921 (2003)

12. Jang, Y.H., Kim, S.S., Lee, J.H.: Effect of different Mn contents on tensile and corrosion behavior of CD4MCU cast duplex stainless steels. Mater. Sci. Eng. A 396, 302-310 (2005)

13. Diqing, W., Jincheng, W., Gaifang, W., Xianyi, C., Linlin, L., Zhigang, F., Gencang, Y.: Effect of Mn on damping capacities, mechanical properties, and corrosion behaviour of high damping Mg-3wt.\% Ni based alloy. Mater. Sci. Eng. A 494, 139-142 (2008)

14. Park, K., Kwon, H.: Effects of Mn on the localized corrosion behavior of $\mathrm{Fe}-18 \mathrm{Cr}$ alloys. Electrochim. Acta 55, 3421-3427 (2010)

15. Pardo, A., Merino, M.C., Coy, A.E., Viejo, F., Arrabal, R., Matykina, E.: Effect of Mo and Mn additions on the corrosion behaviour of AISI 304 and 316 stainless steels in $\mathrm{H}_{2} \mathrm{SO}_{4}$. Corros. Sci. 50, 780-794 (2008)

16. Hyun, P.J., Kwon, H.S.: Development of high Mn-N duplex stainless steel for automobile structural components. Corros. Sci. 50, 404-410 (2008)

17. Stansbury, E.E, Buchanan, R.A.: Fundamentals of Electrochemical Corrosion. ASM International, Ohio (2000)

18. Khojier, K., Savaloni, H.: On the annealing temperature, penetration depth of oxygen and film thickness on the DC and AC electrical properties and nano-structure of Ti thin films. Vacuum 84, 770-777 (2010)

19. Chang, Y.-Y., Wang, D.-Y.: Corrosion behavior of electroless nickel-coated AISI 304 stainless steel enhanced by titanium ion implantation. Surf. Coat. Technol. 200, 2187 (2005) 